\title{
Internal Relationship Interaction of Clothing Industry Cluster
}

\author{
Jinqiang Li \\ Shandong Vocational Institute of Clothing Technology, Tai'an, 271000, China
}

Keywords: Clothing industry, Industry cluster, Internal relationship

\begin{abstract}
Our country has always been a big textile and clothing manufacturer but is inferior to other countries in the aspect of building clothing brands; the most important reason is that there are not many clothing enterprises that can play a supporting role; besides, time and capital accumulation are required for catching up with and surpassing famous brands within a short time. Thus, to develop the clothing industry in our country and narrow the gap with other famous brands, it is required to draw support from enterprises' joint strength, strengthen the mutual cooperation and establish the strongly professional and interactive clothing industry cluster, so as to make Chinese clothing industry more competitive in the global clothing field. This paper mainly analyzes the internal relationship of clothing industry cluster and hereby demonstrates the importance of researching the industry cluster.
\end{abstract}

\section{Introduction}

Industry cluster mainly refers to the interaction relationship of different commodities established within an area due to their close geographical locations or their certain relations, which thereby forms a united and competitive economic organization. The establishment of industry cluster can minimize the enterprise investment cost and form external economies of scale during mutual cooperation and development; more importantly, the industry cluster can facilitate mutual learning of internal personnel and improve the enterprise competitiveness. The market competition in the clothing industry is increasingly fierce, thus it is very necessary to achieve the mutual development and cooperation in the industry by means of industry cluster.

\section{Main features of industry cluster}

Industry cluster is not the simple superposition of many enterprises, but certain reciprocity and universality mechanism formed among enterprises. In general, industry cluster has the following features:

\section{Spatial gathering}

Enterprise gathering involved in industry cluster is mentioned from the perspective of space within a certain area; that is to say, nearby enterprises can gather together to form a cluster; the close geographical locations can greatly reduce the goods transportation cost and speed up the information transfer among enterprises.

\section{Capable of producing special products}

Products produced by the industry cluster have certain features such as strong practicability, and have obvious regional characteristics such as the cashmere industry in Hebei Province; the scale production can be achieved by virtue of regional characteristics.

\section{Very clear work division among enterprises}

For a single form of enterprise cluster, its production efficiency is very low; for many of such single-form enterprise clusters, their products are, in most cases, finished in one production chain. Finished products are also characterized by simplicity and are not very competitive in the market. Thus, an industry cluster with complete work division can quickly gather more manpower, material resources and financial resources, and each part of production is completed in the form of work division. From this point, the work division is very clear. 


\section{Networking tendency of industry cluster}

With the rapid economic development and the revolution of world economic system, the industry cluster is facing the changing environment and will encounter many uncertain factors during development; with the rapid development of information technology, people's demands are gradually diversifying and complicating. Under this tendency, the network-form, interdependent and interactive relationship forms among enterprises in the cluster, and the industry cluster thereby becomes networked. The clothing brand network under the industry cluster is actually formed after combination of individual enterprises, and the interactive network also becomes a competitive advantage of the industry.

Network organization under the industry cluster includes two aspects: horizontal network organization and vertical network organization; vertical network refers to various industrial chains formed through interaction of upstream and downstream enterprises in the industry, for example, the manufacturer, distributor and retailer are closely related and jointly form the network. Under the network background, the benefits and relationship of clustered enterprises are consolidated, which thereby eliminates the obstacles between enterprises, makes the communication smoother, facilitates the information transfer inside the industry cluster, maximizes the utilization of resources and achieves a very good market effect. Horizontal network is contrary to the vertical industry network, and mainly refers to the mutually parallel relationship existing among industries; besides, there are two relations among enterprises, and one of them is the cooperative relationship kept to obtain more market shares. Therefore, network effect is established under the horizontal effect and vertical effect, and the relationship between them is shown in the following Figure 1.

Establishing the all-round cluster interaction mechanism can make all enterprises in the cluster obtain the maximum economic benefits; meanwhile, it is the most obvious characteristic of the industry cluster. The enterprise interaction mechanism of industry cluster mainly includes the following relations: information sharing, win-win cooperation, and communicative cooperation; however, such good relations are not always kept, because all enterprises in the cluster are also competitive in the aspects of resources, market and brands. The cooperative relation of enterprises is established in vertical network and plays a role of catalyst in the network; meanwhile, it is the basis for achieving the unification of various clusters. Network organizations in industry cluster gathers together based mainly on each "knot". In the meantime, each knot in the industry cluster can realize the mutually competitive relationship; such competition appears mainly in product quality, brands and resources. Under such competition, the resources in the cluster are effectively utilized, and it makes the members feel more urgent. In this way, the cluster network will be more energetic and will drive the quick development and growth of the cluster. In brief, each "knot" is under mutual competition, and its operational process can be regarded as a "black box" due to existence of the network organization. Quantitative tools can be used to analyze the network organization relationship of clothing industry cluster, which can provide management personnel with certain reference.

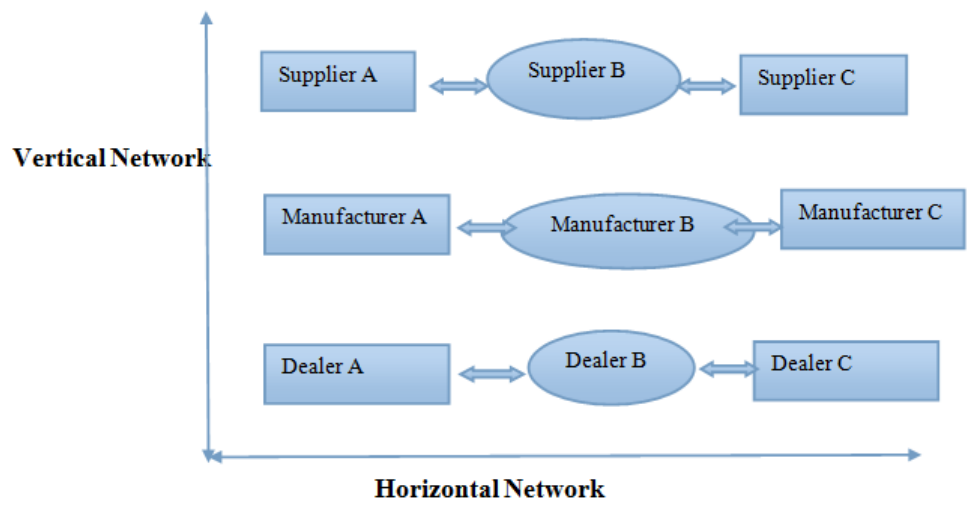

Fig. 1. Vertical and Horizontal Network Structure of Industry Cluster 


\section{Model building}

With the theoretical exposition of industry cluster, it is possible to building the structural equation model on the theoretical basis; by building the structural model of industry cluster, it will be clearer how the network relationship affects the cluster competition model; the structural variables for building the competition model include the following types: sharing relationship, cooperative relationship, competitive relationship, etc.; some assumptions are hereby proposed.

Assumption 1: The enterprise sharing relationship will have a very significant effect on the cluster competitiveness.

Assumption 2: The sharing relationship among enterprises can affect the enterprise's competitiveness.

Assumption 3: The cooperative relationship among enterprises is directly related to the enterprise's competitiveness.

Assumption 4: The enterprise sharing relationship will have certain effect on the internal cooperative relationship.

Assumption 5: The enterprise competitive relationship will affect the competitiveness inside the cluster.

Assumption 6: The enterprise sharing relationship is significantly related to the competitive relationship.

According to the 6 assumptions for the competition model of industry cluster, the assumption model relationships built are shown in the following Figure 2:

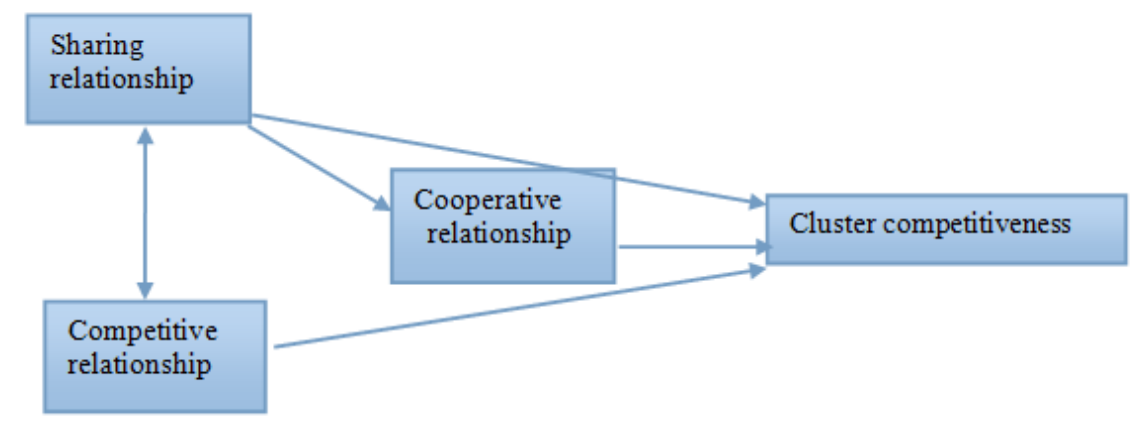

Fig. 2. Assumption Model About the Influence of Cluster Network Relationship on Cluster Competitiveness

\section{Empirical analysis}

\section{Empirical research method and survey design}

There are no specified assumption constraints for the model built for this research, and there is also no error between variables and independent variables. The variable relationship that does not exist independently can be also built on the design software.

Our country's clothing industry develops rapidest in the southern district, and it also develops very fast in the east coastal area due to advantaged geographical location; with the advantaged geographical location, Shanghai is a port for foreign development in our country and develops very fast in the aspect of economy, so that its development in the clothing industry surpasses all other provinces and cities. A clothing factory in Shanghai is taken as an example for this research; this clothing factory has also a close cooperation with a fashion design school in this city; cooperative enterprises develop very well in this industry. In this research, surveyed objects are teachers and students of the fashion design school as well as relevant clothing professionals. There are 200 questionnaires sent out, and 166 pieces of them are collected back; the efficiency of questionnaires is very high. Among the questionnaires collected back, many samples derive from enterprises, thus the data are more reliable. Subjects in these questionnaires include: 6 selective subjects for enterprise cooperation relationship, involving 3 major indicators; 3 indicators for competitive relationship, 
which are of second level, and there are three subjects. All the subject options are of question-and-answer mode; in this research, questionnaires are repeatedly supplemented to make the research more accurate, and the crowds are also more targeted. The following Table 1 shows the contents of questionnaires:

Table 1. Measurement Table About the Influence of Cluster Network Relationship on Cluster Competitiveness

\begin{tabular}{|c|c|c|}
\hline Factor & Cluster Network Relationship & Subject Options \\
\hline \multirow{3}{*}{$\begin{array}{l}\text { Enterprise sharing } \\
\text { relationship }\end{array}$} & Resource sharing & 1. What is your perception about the \\
\hline & & infrastructure of the cluster? \\
\hline & Brand effect sharing & $\begin{array}{l}\text { 2. What is the industry information sharing } \\
\text { degree of clustered enterprises? }\end{array}$ \\
\hline \multirow{3}{*}{$\begin{array}{l}\text { Enterprise } \\
\text { cooperation } \\
\text { relationship }\end{array}$} & $\begin{array}{l}\text { Technological innovation } \\
\text { cooperation }\end{array}$ & $\begin{array}{l}\text { 3. Will the famous brand in the cluster } \\
\text { attract foreign }\end{array}$ \\
\hline & & investors? \\
\hline & Supply chain management & $\begin{array}{l}\text { 4. Will the cluster brand increase the } \\
\text { enterprise's sales volume? }\end{array}$ \\
\hline $\begin{array}{l}\text { Enterprise } \\
\text { competition } \\
\text { relationship }\end{array}$ & Enterprise brand competition & $\begin{array}{l}\text { How about the propaganda competitiveness } \\
\text { of enterprise brand in the cluster? }\end{array}$ \\
\hline \multirow[t]{2}{*}{$\begin{array}{l}\text { Cluster } \\
\text { competitiveness }\end{array}$} & Brand influence & $\begin{array}{l}\text { What is your impression about the integrity } \\
\text { brand passed out by the cluster? }\end{array}$ \\
\hline & Market share & $\begin{array}{l}\text { How about the market sales condition of } \\
\text { products under the cluster? }\end{array}$ \\
\hline
\end{tabular}

\section{Analysis on efficiency factor of measurement table reliability}

As the analysis function of software factor can analyze the reliability of measurement table, uncertain factors can be analyzed with KMO testing methods; the analysis results are: the KMO value is 0.652 , a little higher than 0.6 , thus the selected range is acceptable; the checked value of $\mathrm{F}$ is 0.002 , obviously smaller than 0.4 ; it indicates that the sample data of model is normally distributed, that the correlation is extremely obvious, and that the factor analysis requirements are fully satisfied. The reliability coefficient of this research is 0.715 , which is higher than the standard of 0.6 and indicates that the range is acceptable; it is hereby indicated that the model has a very good internal consistency and a high reliability.

\section{Confirmatory analysis of assumption model}

The special software for handling the structural equation model is AMOS, and this software can analyze multiple variables. The method of model building is to draw images, which is very convenient for use; the software can read SPSS files and data. Thus, AMOS can investigate and analyze the model in a better way, and build the regression model, confirmatory regression model, assumption testing model, etc. between variables on this basis.

\section{Results of assumption verification}

Confirmatory analysis can be carried out for each assumption in the model according to the route between different variables, and the testing results are shown in the following Table:

Table 2. Assumption Testing Results

\begin{tabular}{ccc}
\hline $\begin{array}{c}\text { Assumption } \\
\text { Model }\end{array}$ & Testing Result & Standard Route \\
\hline Assumption 1 & Tenable & \\
\hline
\end{tabular}




\begin{tabular}{lc}
\hline Assumption 2 & Tenable \\
\hline Assumption 3 & Tenable \\
\hline Assumption 4 & Untenable \\
\hline Assumption 5 & Tenable \\
\hline Assumption 6 & Tenable
\end{tabular}

There are totally 6 assumptions put forward for this research, one of which is untenable, indicating that the competitive relationship among enterprises has no direct impact on the enterprise's competitiveness; the remaining 5 assumptions are tenable.

\section{Conclusions and suggestions}

This paper researches the internal relationship of clothing industry cluster, builds the cluster network relationship that can have certain influence on the cluster competitiveness, and establishes the inter-enterprise sharing relationship, cooperative relationship, competitive relationship and cluster competition relationship in the network relationship. The above-mentioned research and description indicate that certain resource, fund and personnel sharing relationship exists among enterprises in the clothing industry, meanwhile, the cooperative relationship also exists; the two relationships play an obvious role in the integrated network development, while the inter-enterprise competitive relationship exists in two forms: healthy competition and vicious competition. Thus, they play a very obvious role in the cluster network.

Each relationship existing in the clothing cluster network will play a different role in the industry development; the sharing relationship and cooperative relationship play an obvious promotion role in the clothing industry development, while other influential organizations in the cluster, such as government and competent department of the industry, can establish a long-term cooperation and mutual trust relationship by means of resource sharing and interaction, so as to make all enterprises in the cluster have breakthroughs in the aspects of technology and management experience, achieve friendly communications in these aspects and greatly strengthen the cluster competitiveness.

Therefore, each enterprise in the clothing industry shall give play to the government's leading role, plan and formulate the market and industry standards. The competition mechanism existing in clothing industry includes two aspects: Healthy competition can make enterprises feel urgent for development, enhance their market competitiveness by improving their own management, technology, talents, etc., strive for setting up the industry brand and also improve the cluster competitiveness; however, the resource waste will also increase after the cluster develops to a certain stage, and the resource competition will appear in the market of the clothing industry, and the cluster will also develop towards the wrong direction of contention. Thus, the government shall carry out the supervision, maintain the market order, and facilitate the development of the clothing market towards the road of systemization and standardization. Organizations themselves in the industry shall also understand the importance of healthy competition, execute the production supervision and quality inspection, and make all techniques reach standards. Communication and cooperation mechanisms appropriate for enterprise development shall be established, and internal personnel shall be periodically organized for study and further education; enterprise leaders shall also strengthen the communication with employees, to draw all employees together for striving for cluster development and forming the integral cluster competitiveness.

\section{Conclusions}

To sum up, internal relationship of clothing industry cluster is reflected in many relationships, in which the most important ones are competition and cooperation; these are two contrary relationships but are also two interactive relationships; thus, correctly understanding each relationship network in 
the cluster will have a very important significance for rational work division among enterprises, proper communication and cooperation, rational fund utilization, etc.

\section{Acknowledgments}

This paper is the development plan subject of Taian Municipal Science and Technology Bureau: Taian Clothing Engineering Research Center 20091003, and the development plan subject of Taian Municipal Science and Technology Bureau: Construction of Clothing Technology Service System for Clothing Enterprises in Taian 20084006.

\section{References}

[1] Gao Changkuan and Hu Shouzhong. Research on Internal Relationship Interaction of Clothing Industry Cluster. Journal of Silk, 2014,51(6):75-80.

[2] Zhang Shengming. Research on Competitive and Cooperative Relationship Between Large Enterprises and Middle and Small-sized Enterprises Under the "Dual Structure" in Textile and Clothing Industry. Donghua University, 2010.

[3] Gao Changkuan and Hu Shouzhong. Empirical Research on Internal Relationship Mechanism of Clothing Industry Cluster Based on Network Theory. Journal of Shanghai University of Engineering Science, 2013,27(4):378-382.

[4] Ma Gang. Empirical Research on Competitive Advantage of Enterprises in Industrial Area from the Strategic Network Perspective -Taking the Two Typical Traditional Advantageous Industry Areas in Zhejiang Province as Examples. Zhejiang University, 2010.

[5] Chen Bo. Research on Competitiveness Influence Mechanism of Textile and Clothing Productive Service Cluster Based on Social Network . Donghua University, 2012 